\title{
Safety and adverse effect profile of colchicine in renal impairment: a systematic review of randomised trials
}

\author{
Julian Yaxley ${ }^{1,2^{*}}$, William Yaxley ${ }^{3}$, Tahira Scott ${ }^{1}$ \\ ${ }^{1}$ Department of Nephrology, Princess Alexandra Hospital, Brisbane, Australia \\ ${ }^{2}$ Griffith University School of Medicine, Gold Coast, Queensland, Australia \\ ${ }^{3}$ Department of Urology, Royal Brisbane and Women's Hospital, Brisbane, Australia
}

\section{A R T I C L E IN F O}

Article Type:

Review

\section{Article History:}

Received: 6 March 2020

Accepted: 9 May 2020

Published online: 13 June 2020

\section{Keywords:}

Colchicine

Chronic kidney disease

Glomerular filtration rate

Myopathy

Cytopaenia

\begin{abstract}
A B S T R A C T
Introduction: Colchicine is an anti-inflammatory drug prescribed for numerous medical conditions. Side effects are frequently encountered, particularly gastrointestinal symptoms. Caution and dose reduction are advised in patients with renal impairment because of a presumed increased risk of side effects. This systematic review intends to summarise the available literature to define the adverse effect profile of colchicine used in patients with kidney disease.

Methods: We conducted a systematic review of randomised clinical trials seeking to evaluate the association between renal impairment and colchicine toxicity. We limited our search to randomised studies in humans in the English language. We allowed colchicine prescribed for any duration, dose or indication.

Results: Our literature search identified a total of 7707 records. Only a single randomised trial was ultimately identified as meeting the inclusion criteria and addressing our research question. In patients with renal impairment, colchicine was not associated with an increased risk of dialysis, time until dialysis, or the incidence of liver function test derangement. We found no data for adverse events such as leukopenia, thrombocytopenia or diarrhoea in the kidney disease subgroup. Data was sparse and of poor quality.

Conclusion: It is widely recommended that colchicine dose be reduced in patients with renal impairment due to an increased risk of drug accumulation and side effects. In our study, we failed to identify any robust clinical research substantiating this association. This is the first systematic review of randomised trials to investigate this link. Further research is required before the safety and tolerability of colchicine in renal disease can be confirmed.
\end{abstract}

Implication for health policy/practice/research/medical education:

There is no robust clinical research substantiating the association between colchicine toxicity and renal impairment. While this may encourage practices to be relaxed, it should continue to be prescribed cautiously in patients with poor renal function until further data becomes available.

Please cite this paper as: Yaxley J, Yaxley W, Scott T. Safety and adverse effect profile of colchicine in renal impairment: a systematic review of randomised trials. J Renal Inj Prev. 2020; 9(4): e28. doi: 10.34172/jrip.2020.28.

\section{Introduction}

Colchicine is an anti-inflammatory drug widely used for a number of medical conditions. Side effects are not uncommon, most frequently including diarrhoea, nausea and abdominal pain. Caution and dose reduction or avoidance are advised in patients with renal impairment because of a presumed increased risk of side effects. While the recommended colchicine dose varies depending on the clinical indication and reference text used, product packaging uniformly advises reduced dosing in patients with a creatinine clearance less than $30 \mathrm{~mL} / \mathrm{min}$ (1). However, the adverse effect profile of colchicine when prescribed in patients with acute renal impairment or chronic kidney disease (CKD) has never been systematically evaluated in the clinical setting. These practices may be unwarranted and result in reduced colchicine treatment efficacy. The aim of this report was to examine the adverse events of colchicine reported in randomised clinical trials when used in patients with renal impairment. 
Methods

Study design

We conducted a systematic literature search of the MEDLINE and Griffith University Library electronic databases. All papers dated from inception up to and including March $3^{\text {rd }} 2020$ were considered for review. We limited our search to randomised clinical trials. We included all randomised studies investigating oral colchicine use for any indication in any population, provided a non-colchicine comparator arm was included. Details regarding colchicine dose and duration were not examined. Only papers written in English were considered. Other inclusion criteria we required were at least some disclosure of adverse side effects, and a subgroup analysis of patients with renal impairment, particularly those with CKD. Renal impairment was defined in our review as any study groups with a documented glomerular filtration rate (GFR) less than $60 \mathrm{~mL} / \mathrm{min} / 1.73 \mathrm{~m}^{2}$, regardless of aetiology or acuity, or those classified by the respective article authors as having renal disease of any type. Any side effects were evaluated but we were particularly interested in gastrointestinal or renal toxicity.

The following entries were utilised for our search strategy; colchicine AND (randomised OR controlled OR placebo). The titles and abstracts of search hits were screened for relevance, with potentially suitable trials selected and duplicates removed independently by the authors. The bibliographies of included studies were also examined for any relevant titles. Discrepancies in the list of articles retrieved for inclusion were discussed among the authors and consensus reached. Data was extracted and tabulated and a meta-analysis attempted, but this was not completed owing to an inadequate study population.

Finally, a quality assessment of the evidence was undertaken using the Oxford quality scoring system and the GRADE Working Group guidelines (Table 1) $(2,3)$. High quality evidence was considered data in which further evidence would be unlikely to change our confidence in the effect. Moderate quality data was evidence for which our confidence could be potentially modified by future research, and poor quality data was evidence for which our confidence in the effect is low and easily modifiable. This method of assessing the literature allowed objective interpretation of the strength of evidence.

Results

Our literature search identified a total of 7707 records.
The titles and abstracts of search hits were screened for relevance and duplicates removed, after which 68 articles were judged potentially suitable for review (Figure 1) (471). Full texts were retrieved and cross-checked against our inclusion criteria. After our systematic review only a single randomised trial was ultimately deemed to meet inclusion criteria and address our research question (71). After some deliberation all authors were in agreement regarding the search results and included articles. Of the remaining 67 studies, all were primarily excluded because of absent subgroup data for a renal impairment cohort (4-71). Additionally, a large number of papers did not describe drug adverse effects.

\section{Study characteristics}

Our single included study was a randomised trial of 3 induction treatment regimens for biopsy-confirmed amyloidosis (71). There were 220 patients randomised into 3 arms of treatment; colchicine monotherapy, colchicine in combination with melphalan and prednisone, or melphalan and prednisone. The dosing regimens were complex and in the colchicine arms included colchicine at doses of $600 \mathrm{mcg}$ twice daily, which was gradually uptitrated to a maximum tolerated dose (Table 2). There were 72 patients in the colchicine group, 71 patients in the triple therapy group, and 77 patients in the prednisone and melphalan combination group.

The included trial was designed to investigate survival outcomes and the subjects were stratified according to principle organ involvement, one of which was renal disease. Other subgroups not germane to our current review were cardiac involvement, neurological disease, hepatopathy, and a miscellaneous group. Patients were assessed every three weeks to assess for adverse drug reactions out to a follow-up time of 1 year.

The renal disease subgroup referred to any patients with amyloidosis on renal biopsy with either normal or slightly abnormal kidney function and no other significant organ involvement, nephrotic syndrome, or advanced renal impairment defined as a serum creatinine greater than $177 \mu \mathrm{mol} / \mathrm{L}$.

\section{Study quality}

The only eligible study was a single-centre trial that randomized patients into 3 study arms. There was no outline on the randomisation or blinding process and there was no placebo cohort. An outline of the patient

Table 1. GRADE Assessment Tool for quality of evidence

\begin{tabular}{lc}
\hline Underlying Methodology & Quality Rating \\
\hline Randomized trials; or double-upgraded observational studies. & High \\
Downgraded randomized trials; or upgraded observational studies. & Moderate \\
Double-downgraded randomized trials; or observational studies. & Low \\
Triple-downgraded randomized trials; or downgraded observational studies; or case series/case reports. & Very low \\
\hline
\end{tabular}




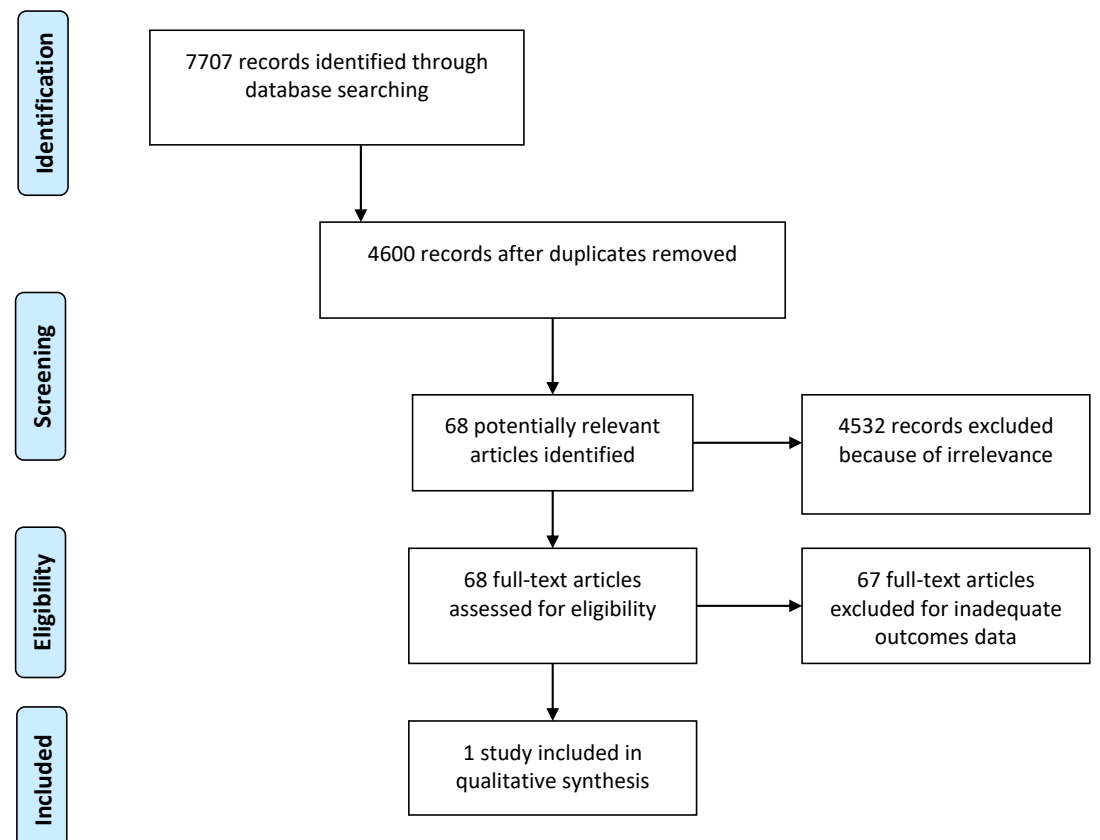

Figure 1. Flow diagram of search strategy.

recruitment procedure was absent except to say that all subjects had amyloidosis confirmed on target organ biopsy. Patient demographics were not explained except for a median age of 64 years. It was stated that some patients were not naïve to treatment, although the therapies and clinical background were not elucidated. It is unknown what portion of subjects were taking colchicine prior to enrolment. It was stated that prescribed drug doses were titrated to maximum tolerated levels however the precise dosing information was not disclosed and therefore could have been very inconsistent. There is no disclosure of the rates of deviation from or crossover between study arms, though there were no dropouts.

Because of a paucity of data, methodological flaws and the possibility of bias, there was unanimous agreement by the authors that the level of evidence obtained in our literature search was low or very low. The Jadad score using the Oxford tool was $1 / 5$, indicating low data quality (2).

\section{Study results}

A total of 105 patients with renal disease were included in

Table 2. Drug dosing regimens randomised in Kyle et al

\begin{tabular}{ll}
\hline Arm & Starting Drug Regimen \\
\hline Colchicine & Colchicine $600 \mathrm{mcg}$ twice daily \\
Colchicine + & $\begin{array}{l}\text { Colchicine } 600 \mathrm{mcg} \text { twice daily + melphalan } 0.15 \\
\mathrm{mg} / \mathrm{kg} \text { once daily for } 1 \text { week every } 6 \text { weeks }+\end{array}$ \\
$\begin{array}{l}\text { predphalan }+ \\
\text { prednisone } 0.8 \mathrm{mg} / \mathrm{kg} \text { once daily for } 1 \text { week every } \\
\text { Melphalan }+\end{array}$ & $\begin{array}{l}\text { Melphalan } 0.15 \mathrm{mg} / \mathrm{kg} \text { once daily for } 1 \text { week every } 6 \\
\text { prednisone }\end{array}$ \\
\hline
\end{tabular}

this paper, of whom 68 received colchicine therapy. Few adverse effect data was outlined for this subgroup. There was no difference in the incidence of dialysis-dependent renal failure, the time until dialysis, or the incidence of liver function test derangement across all groups. The incidence of dialysis was significant at 20.5\% (41 patients) across all groups, which was presumably due to the natural history of renal amyloidosis rather than an adverse outcome of colchicine although this was not clarified. The actual frequency of abnormal liver tests was not quantified. We found no exploration of the typically expected adverse events such as leukopenia, thrombocytopenia or diarrhoea in the renal disease subgroup.

\section{Discussion}

Colchicine is an anti-inflammatory medication, believed to act through inhibition of neutrophil migration, chemotaxis, adhesion and phagocytosis in inflamed tissues (1). It is used frequently in immune diseases such as gout, pericarditis, familial Mediterranean fever and amyloidosis. Colchicine and its metabolites are predominantly excreted in faeces, while undergoing approximately $15 \%$ renal clearance (72). In experimental studies the colchicine half-life is reported to increase from approximately 4 hours in healthy subjects to 20 hours in patients with endstage renal failure (72). Consequently, the manufacturer recommends a dose reduction in patients with renal impairment due to the risk of drug accumulation and side effects $(1,72)$. The commonest reported adverse effects are gastrointestinal symptoms, peripheral neuropathy and myopathy, and cytopaenia $(1,71)$.

It is the authors' experience that in clinical practice 
colchicine is generally prescribed cautiously in patients with renal impairment. This may reduce colchicine's efficacy in that context, and although this is consistent with general guidelines the safety and tolerability of colchicine when used in this patient population has not been systematically evaluated in the literature. After a systematic review of the literature, we were unable to find data in randomised studies demonstrating an increased incidence of adverse effects with kidney disease. Only a single randomised clinical trial by Kyle and colleagues was identified which in some way addressed this research question (71). In their cohort of patients with renal disease secondary to amyloidosis, defined as nephrotic syndrome or raised creatinine without extra-renal manifestations, colchicine was not associated with an elevated risk of dialysis, reduced dialysis-free survival, or deranged liver tests. This finding should be interpreted with caution given lack of a placebo group and the paucity of information provided about the medical context of the patients' renal background. No data were provided for adverse effects such as diarrhoea, nausea, or cytopaenia.

It is important to recognise that an absence of clinical data demonstrating increased adverse events when colchicine is used in acute kidney injury or CKD does not equate to evidence of safety or tolerability. There are sound pharmacokinetic and physiological arguments for prescribing colchicine carefully when creatinine clearance is reduced. As mentioned, pharmacologic research confirms that the half-life of colchicine increases with falling creatinine. There are many observational reports of colchicine toxicity attributed to renal insufficiency $(73,74)$. Conversely, there are also large cohort studies which have not identified an association between kidney disease and colchicine toxicity (75).

There is no specific guidance for the reporting of systematic literature reviews in which no studies are retrieved meeting the inclusion criteria. These so-called "empty reviews" may still be a source of useful information. We performed rigorous analysis of all high-level evidence available and have ensured diligent documentation of all excluded trials in our reference list. Our systematic search discovered only a single eligible article, rendering meaningful conclusions elusive. Furthermore, that paper is itself not without methodologic flaws. Although follow up was excellent, it was conducted at a single hospital with unknown patient demographics, and previous treatments and the patients' medical comorbidities were not propensity-matched. The predominant adverse event mentioned, being the need for dialysis, was arguably a measure of treatment outcome rather than a true side effect.

Based on two separate assessment tools, the quality and certainty of evidence gathered in our review must be graded as low or very low. It is not known whether loosening our inclusion criteria would have been helpful, or would have confused the data further and lead to greater dilution in the strength of evidence.

\section{Conclusion}

This is the first systematic review examining the adverse effect profile of colchicine in renal insufficiency in randomised trials. Although our literature review was comprehensive, evidence was scant and data quality was poor. It is widely recommended that colchicine dose be reduced in patients with acute or chronic renal impairment due to an increased risk of drug accumulation and side effects. In our study, we failed to identify any robust clinical research demonstrating this association. Although an absence of evidence does not definitively confirm drug safety, based on our study clinicians can probably prescribe colchicine with some reassurance in patients with kidney disease. Further research is warranted before strong recommendations to change practice can be supported.

\section{Authors' contribution}

JY was the principle investigator of this study. JY and TS were included in preparing the concept and design. JY and WY revised the manuscript and critically evaluated the intellectual contents. All authors participated in preparing the final draft of the manuscript, revised the manuscript and critically evaluated the intellectual contents. All authors have read and approved the content of the manuscript and confirmed the accuracy or integrity of any part of the work.

\section{Conflicts of interest}

There are no conflicts of interest to declare.

\section{Ethical considerations}

Ethical issues (including plagiarism, data fabrication, double publication) have been completely observed by the authors.

\section{Funding/Support}

None.

\section{References}

1. Australian Medicines Handbook [Internet]. Adelaide: Australian Medicines Handbook Pty Ltd;2018. [updated 2020 Jan; cited 2020 Mar 10]; Available from: https:// amhonline-amh-net-au.eu1./chapters/rheumatologicaldrugs/drugs-gout/other-drugs-gout/colchicine.

2. Jadad A, Moore R, Carroll D, Jenkinson C, Reynolds D, Gavaghan D, et al. Assessing the quality of reports of randomised clinical trials: is blinding necessary? Control Clin Trials 1996;17:1-12. doi: 10.1016/0197-2456(95)00134-4

3. Atkins D, Best D, Briss P, Eccles M, Falck-Ytter Y, Flottorp $S$, et al. Grading quality of evidence and strength of recommendations. Br Med J. 2004;328:1-8. doi: 10.1136/ bmj.328.7454.1490.

4. Adhami J, Basho J. Treatment with colchicine and survival 
of patients with ascitic cirrhosis: a double-blind randomized trial. Panminerva Med. 1998;40:75-81.

5. Afdhal N, Levine R, Brown R, Freilich B, O’Brien M, Brass C. Colchicine versus PEG-interferon alfa $2 \mathrm{~b}$ long term therapy: results of the 4 year copilot trial. J Hepatol. 2008;48:4.

6. Ahmadieh H, Nourinia R, Ragati Haghi A, Ramezani A, Entezari M, Rahmani G, et al. Oral colchicine for prevention of proliferative vitreoretinopathy:a randomized clinical trial. Acta Ophthalmol. 2015;93:171-72. doi: 10.1111/aos.12429

7. Almasio P, Floreani A, Chiaramonte M, Provenzano G, Battezzati P, Crosignani A, et al. Multicentre randomized placebo-controlled trial of urs odeoxycholic acid with or without colchicine in symptomatic primary biliary cirrhosis. Aliment Pharmacol Ther. 2000;14:1645-52. doi: 10.1046/j.1365-2036.2000.00869.x

8. Antoniou K, Nicholson A, Dimadi M, Malagari K, Latsi P, Tzanakis N, et al. Long term clinical effects of IFN- $\gamma-1 b$ and colchicine in idiopathic pulmonary fibrosis. Eur Resp. J 2006;28:496-504. doi: 10.1183/09031936.06.00032605

9. Aran S, Malekzadeh S, Seifirad S. A double-blind randomised controlled trial appraising the symptom-modifying effects of colchicine on osteoarthritis of the knee. Clin Exp Rheumatol. 2011;29:513-18.

10. Battezzati P, Zuin M, Crosignani A, Allocca M, Invernizzi P, SelmiC, et al. Ten-year combination treatment with colchicine and ursodeoxycholic acid for primary biliary cirrhosis:a double blind, placebo-controlled trial on symptomatic patients. Aliment Pharmacol Ther. 2001;15:1427-34. doi: 10.1046/j.1365-2036.2001.01018.x

11. Bessisow A, Agzarian J, Shargall Y, Srinathan S, Neary J, Tandon V, et al. Colchicine for prevention of perioperative atrial fibrillation in patients undergoing lung resection surgery:a pilot randomised controlled study. Eur J Cardiothorac Surg. 2018;53:945-51. doi: 10.1093/ejcts/ ezx 422

12. Bodenheimer H, Schaffner F, Pezzullo J. Evaluation of colchicine therapy in primary biliary cirrhosis. Gastroenterology 1988;95:124-29. doi: 10.1016/00165085(88)90300-9

13. Borstad G, Bryant L, Abel M, Scroggie D, Harris S, Alloway J. Colchicine for prophylaxis of acute flares when initiating allopurinol for chronic gouty arthritis. J Rheumatol. 2004;31:2429-32.

14. Buligescu L, Voiculescu M. Randomized controlled clinical trial of colchicine in the long term treatment of liver cirrhosis. J Hepatol. 1989;9:12.

15. Cohen A, Girard W, Mclarty J, Starcher B, Davis D, Stevens M, et al. A controlled trial of colchicine to reduce the elastase load in the lungs of ex-cigarette smokers with chronic obstructive pulmonary disease. Am Rev Respir Dis. 1991;143:1038-43. doi: 10.1164/ajrccm/143.5_Pt_1.1038

16. Colman J, Cromie S, Cox J, Roberts S, Dudley E, Dudley F. The natural history of alcoholic cirrhosis:effect of colchicine. Hepatology. 1998;28:510.

17. Cortez-Pinto H, Alexandrino P, Camilo M, Gouviea-Oliveira A, Santos P, Alves M, et al. Lack of effect of colchicine in alcoholic cirrhosis:final results of a double blind randomised trial. Eur J Gastroenterol Hepatol. 2002;14:377-81. doi: 10.1097/00042737-200204000-00007

18. Das S, Mishra K, Ramakrishnan S, Srivastava R, Agarwal GG, Singh R, et al. A randomised controlled trial to evaluate the slow acting symptom modifying effects of a regimen containing colchicine in a subset of patients with osteoarthritis of the knee. Osteoarthr Cartil. 2002;10:247-52. doi: 10.1053 /joca.2002.0516

19. Davatchi F, Sadeghi Abdollahi B, Tehrani Banihashemi A, Shahram F, Nadji A, Shams H, et al. Colchicine versus placebo in Behcet's disease:randomised, double-blind, controlled crossover trial. Mod Rheumatol. 2009;19:542-49. doi: 10.1007/s10165-009-0200-2

20. Deftereos S, Giannopoulos G, Raisakis K, Kossyvakis C, Kaoukis A, Panagopoulou V, et al. Colchicine treatment for the prevention of bare metal stent restenosis in diabetic patients. J Am Coll Cardiol. 2013;61:1679-85. doi: 10.1016/j. jacc.2013.01.055

21. Deftereos S, Giannopoulos G, Efremidis M, Kossyvakis C, Katsivas A, Panagopoulou V, et al. Colchicine for prevention of atrial fibrillation recurrence after pulmonary vein isolation:mid-term efficacy and effect on quality of life. Heart Rhythm. 2014;11:620-8. doi: 10.1016/j.hrthm.2014.02.002.

22. Demdowich A, Levine JA, Onyekaba GI, Khan SM, Chen KY, Brady SM, et al. Effects of colchicine in adults with metabolic syndrome:a pilot randomised controlled trial. Diabetes Obes Metab. 2019;21:1642. doi: 10.1111/dom.13702

23. Dinarello C, Wolff SM, Goldfinger SE, Dale DC, Alling DW. Colchicine therapy for familial Mediterranean fever. A double-blind trial. N Engl J Med. 1974;291:934-37.

24. Douglas W, Ryu JH, Swensen SJ, Offord KP, Schroeder DR, Caron GM, et al. Colchicine versus prednisone in the treatment of idiopathic pulmonary fibrosis:a randomized prospective study. Am J Respir Crit Care Med. 1998;158:2205. doi: 10.1056/NEJM197410312911804

25. Fish J, Peters SP, Chambers CV, McGeady SJ, Epstein $\mathrm{KR}$, Boushey HA, et al. An evaluation of colchicine as an alternative to inhaled corticosteroids in moderate asthma. Am J Respir Crit Care Med. 1997;156:1165-71. doi: 10.1164/ ajrccm.156.4.9703012.

26. Ikeda T, Tozuka S, Noguchi O, Kobayashi F, Sakamoto S, Marumo F, et al. Effects of additional administration of colchicine in ursodeoxycholic acid-treated patients with primary biliary cirrhosis:a prospective randomized study. J Hepatol. 1996;24:88-94. doi: 10.1016/s0168-8278(96)801917.

27. Imazio M, Bobbio M, Cecchi E, Demarie D, Demichelis $\mathrm{B}$, Pomari $\mathrm{F}$, et al. Colchicine in addition to conventional therapy for acute pericarditis:results of the colchicine for acute pericarditis trial. Circulation. 2005;112:2012-16. doi: 10.1161/CIRCULATIONAHA.105.542738.

28. Imazio $M$, Trinchero $\mathrm{R}$, Brucato $\mathrm{A}$, Rovere $\mathrm{ME}$, Gandino A, Cemin R, et al. Colchicine for the prevention of postpericardiotomy syndrome:a multicentre randomised doubleblind placebo-controlled trial. Eur Heart J. 2010;31:2749-54. doi: 10.1093/eurheartj/ehq319.

29. Imazio M, Brucato A, Cemin R, Ferrua S, Belli R, Maestroni $S$, et al. Colchicine for recurrent pericarditis:a randomised trial. Ann Intern Med. 2011;155:409-14. doi: 10.7326/00034819-155-7-201110040-00359.

30. Imazio M, Brucato A, Cemin R, Ferrua S, Maggiolini S, Beqaraj F, et al. A randomised trial of colchicine for acute pericarditis. N Engl J Med. 2013;312:1522-28. doi: 10.1056/ NEJMoa1208536.

31. Imazio M, Brucato A, Ferrazzi P, Pullara A, Adler Y, Barosi A, et al. Colchicine for the prevention of post-pericardiotomy syndrome and postoperative atrial fibrillation. JAMA. 2014;312:1016-23. doi: 10.1001/jama.2014.11026

32. Imazio M, Belli R, Brucato A, Cemin R, Ferrua S, Beqaraj F, et al. Efficacy and safety of colchicine for the treatment of multiple recurrences of pericarditis:a multicentre, 
double-blind, placebo-controlled, randomised trial. Lancet. 2014;383:2232-37. doi: 10.1016/S0140-6736(13)62709-9

33. Kaplan M, Alling DW, Zimmerman HJ, Wolfe HJ, Sepersky RA, Hirsch GS, et al. A prospective trial of colchicine for primary biliary cirrhosis. N Engl J Med. 1986;315:1448-54. doi: 10.1056/NEJM198612043152304

34. Kaplan M, Schmid C, Provenzale D, Sharma A, Dickstein G, McKusick A. A prospective trial of colchicine and methotrexate in the treatment of primary biliary cirrhosis. Gastroenterology. 1999;117:1173-80. doi: 10.1016/s00165085(99)70403-8.

35. Kershenobich D, Uribe M, Suarez GI, Rojkind M. Treatment of cirrhosis with colchicine:a randomized trial. Gastroenterology. 1976;70:128.

36. Rambaldi A, Gluud C. Colchicine for alcoholic and nonalcoholic liver fibrosis and cirrhosis. Cochrane Database Syst Rev. 2001;(3):CD002148.

37. Kershenobich D, Vargas F, Garcia-Tsao G, Perez Tamayo R, Gent M, Rojkind M. Colchicine in the treatment of cirrhosis of the liver. N Engl J Med. 1988;318:1709-13. doi: 10.1056/ NEJM198806303182602.

38. Kyle R, Greipp P, Garton J, Gertz M. Primary systemic amyloidosis. Comparison of melphalan/prednisone versus colchicine. Am J Med. 1985;79:708-16. doi: 10.1016/00029343(85)90521-2.

39. Leung Y, Haaland B, Huebner JL, Wong SBS, Tjai M, Wang C, et al. Colchicine lack of effectiveness in symptom and inflammation modification in knee osteoarthritis: a randomised controlled trial. Osteoarthr Cartil. 2018;26:63140. doi: 10.1016/j.joca.2018.01.026

40. Liebenberg J, Dodd C, Olivier L. A prospective investigation into the effect of colchicine on tuberculous pericarditis. Cardiovasc J Afr. 2016;27:350-55. doi: 10.5830/CVJA-2016035

41. Lin D, Sheen I, Chu C, Liaw Y. A prospective randomized trial of colchicine in prevention of liver cirrhosis in chronic hepatitis B patients. Aliment Pharm Ther. 1996;10:961-66. doi: $10.1046 / j .1365-2036.1996 .98270000 . x$.

42. Lukina G. Treatment of renal reactive amyloidosis in rheumatic diseases with dimethyl sulfoxide and colchicine. Zeitschrift für Rheumatologie. 1995;54:377.

43. Masuda K, Nakajima A, Urayama A, Nakae K, Kogure $\mathrm{M}$, Inaba G. Double-masked trial of cyclosporin versus colchicine and long-term open study of cyclosporin in Behcet's disease. Lancet. 1989;1:1093-96. doi: 10.1016/s01406736(89)92381-7.

44. McKendry R, Kraag G, Seigel S, al-Awadhi A. Therapeutic value of colchicine in the treatment of patients with psoriatic arthritis. Ann Rheum Dis. 1993;52:826-28. doi: 10.1136/ ard.52.11.826.

45. Morgan T, Weiss DG, Nemchausky B, Schiff ER, Anand B, Simon F, et al. Colchicine treatment of alcoholic cirrhosis:a randomized, placebo-controlled clinical trial of patient survival. Gastroenterology. 2005;128:882-90. doi: 10.1053/j. gastro.2005.01.057.

46. Muntoni S, Rojkind M, Muntoni S. Colchicine reduces procollagen III and increases pseudocholinesterase in chronic liver disease. World J Gastroenterol. 2010;16: 2889-94. doi: 10.3748/wjg.v16.i23.2889.

47. Nidorf S, Eikelboom J, Budgeon C, Thompson P. Lowdose colchicine for secondary prevention of cardiovascular disease. J Am Coll Cardiol. 2013;61:404-10. doi: 10.1016/j. jacc.2012.10.027.

48. Nikolaidis N, Kountouras J, Giouleme O, Tzarou V, Chatzizisi
O, Patsiaoura K, et al. Colchicine treatment of liver fibrosis. Hepato-gastroenterology. 2006;53:281-85.

49. O'Keefe J, McCallister B, Bateman T, Kuhnlein D, Ligon R, Hartzler G. Ineffectiveness of colchicine for the prevention of restenosis after coronary angioplasty. J Am Coll Cardiol. 1992;19:1597-600. doi: 10.1016/0735-1097(92)90624-v

50. Olsson R, Broomé U, Danielsson A, Hägerstrand I, Järnerot G, Lööf L, et al. Colchicine treatment of primary sclerosing cholangitis. Gastroenterology. 1995;108:1199-203. doi: 10.1016/0016-5085(95)90220-1

51. Pakfetrat A, Mansourian A, Momen-Heravi F, Delavarian Z, Momen-Beitollahi J, Khalilzadeh O, et al. Comparison of colchicine versus prednisolone in recurrent aphthous stomatitis: A double-blind randomized clinical trial. Clin Invest Med. 2010;33:189-95. doi: 10.25011/cim.v33i3.13725

52. Parise E, Chehter L, Noguiera M. Colchicine in chronic liver disease of alcoholic etiology. Double-blind, randomized study of its effects on blood levels of plasma proteins and clinical course in patients. Revista da Associacao Medica Brasileira. 1995;41:207-12.

53. Paulus H, Schlosstein LH, Godfrey RG, Klinenberg JR, Bluestone R. Prophylactic colchicine therapy of intercritical gout. Arthritis Rheum. 1974;17:609-74. doi: 10.1002/ art. 1780170517

54. Poupon R, Huet P, Poupon R, Bonnand A, Nhieu J, Zafrani E. A randomized trial comparing colchicine and ursodeoxycholic acid combination to ursodeoxycholic acid in primary biliary cirrhosis. Hepatology. 1996;24: 1098-103.

55. Raedsch R, Stiehl A, Walker S, Scherrmann J, Kommerell B. Controlled study on the effects of a combined ursodeoxycholic acid plus colchicine treatment in primary biliary cirrhosis. Zeitschrift für Gastroenterologie. 1992; 30: 55-7.

56. Reinhardt M, Jorke D, Jahn G, Krombholz B, Müller A, Machnik G, et al. Colchicine therapy of fibrosing liver diseases: report of a randomized double-blind study. Deutsche Zeitschrift für Verdauungs- und Stoffwechselkrankheiten. 1986;46:257-75.

57. Roche N, Lurie A, Authier S, Dusser DJ. Nasal response to capsaicin in patients with allergic rhinitis and in healthy volunteers: effect of colchicine. Am J Respir Crit Care Med. 1995;151:1151-58. doi: 10.1164/ajrccm.151.4.7697245

58. Roddy E, Clarkson K, Blagojevic-Bucknall $\mathrm{M}$, Mehta $\mathrm{R}$, Oppong R, Avery A, et al. Open-label randomised pragmatic trial (CONTACT) comparing naproxen and lowdose colchicine for the treatment of gout flares in primary care. Ann Rheum Dis. 2019;79:276-84. doi: 10.1136/ annrheumdis-2019-216154

59. Sambola A, Roca Luque I, Mercé J, Alguersuari J, FranciscoPascual J, García-Dorado D, et al. Colchicine Administered in the First Episode of Acute Idiopathic Pericarditis: A Randomized Multicenter Open-label Study. Rev Esp Cardiol. 2019;72:709-16. doi: 10.1016/j.rec.2018.11.016

60. Schlesinger N, Mysler E, Lin HY, De Meulemeester M, Rovensky J, Arulmani U, et al. Canakinumab reduces the risk of acute gouty arthritis flare during initiation of allopurinol treatment: results of a double-blind, randomised study. Ann Rhem Dis. 2011;70: 1264-71. doi: 10.1136/ard.2010.144063

61. Schnebel B, Simmons J. The use of oral colchicine for low back pain: a double-blind study. Spine. 1988;13:354-57. 10.1097/00007632-198803000-00023.

62. Siedeman P, Fjellner B, Johannesson A. Psoriatic arthritis treated with oral colchicine. J Rheumatol. 1987;14:777-79.

63. Tardif J, Kouz S, Waters DD, Bertrand OF, Diaz R, Maggioni 
A, et al. Efficacy and safety of low dose colchicine after myocardial infarction. New Engl J Med. 2019;381:2497-3005. doi: 10.1056/NEJMoa1912388

64. Terkeltaub R, Furst DE, Bennett K, Kook KA, Crockett R, Davis M. High versus low dosing of oral colchicine for early acute gout flare. Arthritis Rheum. 2010; 62:1060-68. doi: $10.1002 /$ art. 27327

65. Trinchet J, Beaugrand M, Callard P, Hartmann DJ, Gotheil C, Nusgens BV, et al. Treatment of alcoholic hepatitis with colchicine. Results of a randomized double blind trial. Gastroenterologie Clinique et Biologique. 1989;13:551-5.

66. Vuoristo M, Färkkilä M, Karvonen AL, Leino R, Lehtola J, Mäkinen J, et al. A placebo-controlled trial of primary biliary cirrhosis treatment with colchicine and ursodeoxycholic acid. Gastroenterology. 1995;108:1470-8. doi: 10.1016/00165085(95)90696-7.

67. Wang Y, Lee SD, Hsieh MC, Lin HC, Lee FY, Tsay SH, et al. A double-blind randomized controlled trial of colchicine in patients with hepatitis B virus-related postnecrotic cirrhosis. J Hepatol. 1994;21:872-7. doi: 10.1016/s01688278(94)80252-1.

68. Wang Y, Wang L, Li E, Li Y, Wang Z, Sun X, et al. Chuanhu anti-gout mixture versus colchicine for acute gouty arthritis: a randomised, double-blind, double-dummy, no-inferiority trial. Int J Med Sci. 2014;11:880-85. doi: 10.7150/ijms.9165.
69. Warnes T, Smith A, Lee F, Haboubi N, Johnson P, Hunt L. A controlled trial of colchicine in primary biliary cirrhosis. Trial design and preliminary report. J Hepatol. 1987;5:1-7.

70. Yurdakul S, Mat C, Tüzün Y, Ozyazgan Y, Hamuryudan $\mathrm{V}$, Uysal $\mathrm{O}$, et al. A double-blind trial of colchicine in Behcet's syndrome. Arthritis Rheum. 2001;44:268692. doi: 10.1002/1529-0131(200111)44:11<2686::aid$\operatorname{art} 448>3.0 . c 0 ; 2-\mathrm{h}$

71. Kyle R, Gertz MA, Greipp PR, Witzig TE, Lust JA, Lacy $\mathrm{M}$, et al. A trial of three regimens for primary amyloidosis: colchicine alone, melphalan and prednisone, and melphalan, prednisone and colchicine. N Engl J Med. 1997;336 : 120207. doi: 10.1056/NEJM199704243361702.

72. The Renal Drug Reference Guide. 1st ed. Adelaide: Kidney Health Australia; 2007. p. 436.

73. Medani S, Wall C. Colchicine toxicity in renal patients - are we paying attention? Clin Nephrol. 2016;86:100-05. doi: $10.5414 / \mathrm{CN} 108343$.

74. Wilbur K, Makowsky M. Colchicine myotoxicity: case reports and literature review. Pharmacotherapy. 2004;24: 1784-92. doi: 10.1592/phco.24.17.1784.52334.

75. Solak Y, Atalay H, Biyik Z, Alibasic H, Gaipov A, Guney F, et al. Colchicine toxicity in end-stage renal disease patients: a case control study. Am J Ther. 2014;21:189-95. doi: 10.1097/ MJT.0b013e31825a364a.

Copyright $\odot 2020$ The Author(s); Published by Nickan Research Institute. This is an open-access article distributed under the terms of the Creative Commons Attribution License (http://creativecommons.org/licenses/by/4.0), which permits unrestricted use, distribution, and reproduction in any medium, provided the original work is properly cited. 